\title{
Article
}

\section{Optimal Maintenance Policy for Offshore Wind Systems}

\author{
Vincent F. Yu ${ }^{1,2}$ (D), Thi Huynh Anh Le ${ }^{1,3}$, Tai-Sheng Su ${ }^{4}$ and Shih-Wei Lin 5,6,7,*(D) \\ 1 Department of Industrial Management, National Taiwan University of Science and Technology, \\ Taipei 106, Taiwan; vincent@mail.ntust.edu.tw (V.F.Y.); D10901814@mail.ntust.edu.tw (T.H.A.L.) \\ 2 Center for Cyber-Physical System Innovation, National Taiwan University of Science and Technology, \\ Taipei 106, Taiwan \\ 3 Faculty of Project Management, The University of Danang, University of Science and Technology, \\ Danang 550000, Vietnam \\ 4 Department of Industrial Management, National Pingtung University of Science and Technology, \\ Pingtung 912, Taiwan; tyson@mail.npust.edu.tw \\ 5 Department of Information Management, Chang Gung University, Taoyuan 333, Taiwan \\ 6 Department of Industrial Engineering and Management, Ming Chi University of Technology, \\ New Taipei 243, Taiwan \\ 7 Department of Neurology, Linkou Chang Gung Memorial Hospital, Taoyuan 333, Taiwan \\ * Correspondence: swlin@mail.cgu.edu.tw; Tel.: +886-3-211-8800
}

\section{check for}

updates

Citation: Yu, V.F.; Le, T.H.A.; Su, T.-S.; Lin, S.-W. Optimal Maintenance Policy for Offshore Wind Systems. Energies 2021, 14, 6082. https:// doi.org/10.3390/en14196082

Academic Editor: Eugen Rusu

Received: 9 August 2021

Accepted: 14 September 2021

Published: 24 September 2021

Publisher's Note: MDPI stays neutral with regard to jurisdictional claims in published maps and institutional affiliations.

Copyright: (c) 2021 by the authors. Licensee MDPI, Basel, Switzerland. This article is an open access article distributed under the terms and conditions of the Creative Commons Attribution (CC BY) license (https:// creativecommons.org/licenses/by/ $4.0 /)$.

\begin{abstract}
Employing maintenance threshold plays a critical step in determining an optimal maintenance policy for an offshore wind system to reduce maintenance costs while increasing system reliability. Considering the limited works on this topic, we propose a two-stage procedure to determine the optimal maintenance thresholds for multiple components of an offshore wind power system in order to minimize maintenance costs while achieving the highest possible system reliability. First, using genetic algorithms, a dynamic strategy is developed to determine the maintenance thresholds of individual components where the cost of maintenance and the rate of failure are critical. Then, fuzzy multi-objective programming is applied to find the system's optimal maintenance threshold considering all components. A variety of factors including weather conditions, system reliability, power generation losses, and electricity market price are carefully considered to enhance the system's reliability and reduce the costs of maintenance. When maintenance threshold results are compared, component-wise versus system-wise, an average system savings of $1.19 \%$ for maintenance cost is obtained while the system reliability is increased by $1.62 \%$ on average.
\end{abstract}

Keywords: offshore wind system; fuzzy multi-objective programming; failure rate; maintenance threshold; optimal maintenance policy

\section{Introduction}

Global warming and conventional energy resources have been in the spotlight due to the latter's scarcity and their negative environmental impact. The situation has led to new energy resources being discovered to improve human life and the natural environment. Renewable energy resources have been promoted for their tremendous potential as a solution for alleviating environmental pollution caused by conventional energy resources. Among the former, wind energy has received seemingly the most interest and investment from many countries. The Global Wind Energy Council (GWEC) reported that annual capacity installation rose from 2015 to 2020 (as shown in Figure 1) [1]. For instance, from the GWEC report in 2020, the installed capacity of wind farms has increased from 435,284 GW in 2015 to more than $650 \mathrm{GW}$ in 2019 and about $744 \mathrm{GW}$ in 2020 . Wind farms reached a global installed capacity of 744 GW in 2020, with a net installed capacity of 93 GW added that year [1]. Offshore wind systems are located in harsher conditions, so the costs of installation and maintenance are very high [2,3]. Lin et al. [4] noted that the maintenance of an offshore wind turbine accounts for more than $30 \%$ of the total cost of its life cycle. 
The maintenance costs of an offshore wind system are two to three times more than that of an onshore wind system according to Tyler et al. [5]. Ren et al. [6] pointed out that maintenance has a significant impact on the duration of downtime during the lifetime of an offshore wind farm. Moreover, maintenance activities also lead to considerable increases in energy cost. In order to enhance the cost efficiency of an offshore wind system, an improved maintenance policy is essential to lower maintenance costs. Efficient maintenance strategies will reduce power generation losses and downtime.

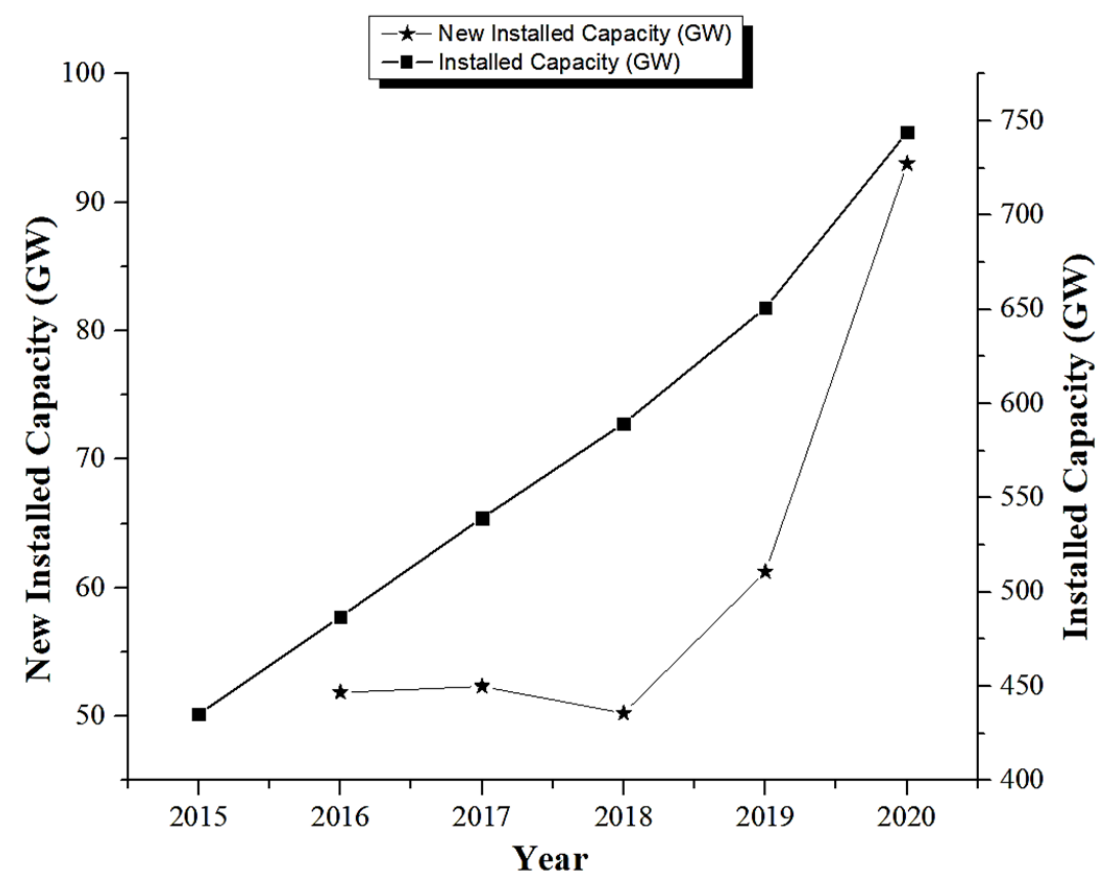

Figure 1. Global capacity installation from 2015 to 2020.

The maintenance of any product extends the product's lifespan, thus increasing the system's availability and reliability. Inadequate maintenance leads to an increasing failure rate and a deterioration of system reliability. However, too many maintenance activities can enhance system reliability, but may increase maintenance cost excessively. Therefore, it is necessary to determine a reasonable maintenance strategy with a possible maintenance threshold to increase system reliability while reducing the total maintenance cost. Ren et al. [6] mentioned that a reasonable maintenance strategy plays an indispensable role of offshore wind system in daily operations. The purpose of the maintenance strategy is to maximize economic benefits, extend component lifespan, and reduce the number of emergency repairs. According to Panneerselvam et al. [7], the objective of maintenance is to maximize the life cycle time of a system, minimize the overall operation cost by reducing scraps and wastage, and preserve the value of a system through a reduction of deterioration.

Existing maintenance strategies for wind systems consist of three categories: corrective maintenance, preventive maintenance, and condition-based maintenance. Kerres et al. [8] presented that corrective maintenance may reduce the number of inspections and repairs of a wind system, but results in higher failure rates, leading to worse system reliability than other maintenance strategies. Unexpected failures may increase the cost more than the expected downtime [6]. Therefore, corrective maintenance is more suitable for repairing a simple machine than a complex system likes wind turbines or should carried out when preventive maintenance is very costly to perform. Additionally, a predetermined maintenance strategy is carried out if machine failures do not have a prevalent random occurrence of failure of breakdown, as noted by Tuyet et al. [9]. According to Ren et al. [6], preventive maintenance based on a predetermined period is considered as a more advanced 
approach. Optimizing the selection of the specified interval can help, in turn, to optimize the preventive maintenance strategies. Preventive maintenance brings various advantages such as avoiding unplanned maintenance, combining maintenance and repairs, optimizing maintenance tasks, and minimizing the impact of unpredictable weather compared to corrective maintenance. A condition-based maintenance strategy which uses condition monitoring system to check system health can be adopted when the equipment requires high-cost estimation and production disruption. In condition-based maintenance, sensors are utilized to collect data about the condition of the wind turbine, so this approach increases system cost and complexity as well as introducing new problems such as sensor failures and misreporting. Additionally, it has challenges to distinguish between real and fake damage. However, a mixed maintenance strategy should be utilized to avoid the disadvantages of each type of maintenance strategy, as shown by Bagshaw et al. [10].

Moreover, determining the maintenance threshold is an important step in determining maintenance policy. Zhang et al. [11] illustrated that maintenance activities should be conducted when the designed maintenance index reaches a given threshold. Besides, Kang et al. [12] mentioned that an opportunistic maintenance strategy aims to identify the best time for maintenance and improve the system's profitability. A maintenance decision depends on the maintenance threshold. Hence, the value of the maintenance threshold directly impacts the maintenance scheduling and thus influences the maintenance cost and reliability of the system. Maintenance policies are established based on an optimal maintenance threshold to minimize maintenance cost while sustaining system reliability, thereby maximizing the cost effectiveness of the maintenance process. Tuyet et al. [9] stated that an efficient maintenance policy should be conducted based on practical factors, including system availability, cost efficiency, weather conditions, duration of maintenance, power loss due to maintenance, and market price of electricity, to improve reliability. Moreover, the maintenance policies should be adapted either for a single component of a wind turbine or for multiple components of multiple wind turbines in an offshore wind system. Therefore, the maintenance threshold should be determined based on such practical factors and multiple components of an offshore wind power system should be considered to enhance the efficiency of the maintenance policy.

A large number of studies on maintenance strategies for wind energy have been conducted. The first maintenance strategy is promoted by Rander et al. [13] and Mccall et al. [14]. Zhou et al. [15] developed an opportunistic preventive maintenance scheduling heuristic that can be applied to multi-unit series systems using dynamic programming in which imperfect effects are incorporated into the maintenance actions. Di et al. [16] applied opportunistic maintenance information to a preventive maintenance decision process to build an optimization model. Zhong et al. [17] proposed a non-linear multi-objective programming model that considers thirteen families of constraints for offshore wind farms preventive maintenance and utilizes genetic algorithm II to effectively solve the model. However, in the field of wind turbines there are scant studies on maintenance policy with optimal maintenance threshold for multiple components of multi-wind turbines. Do et al. [18] proposed an adaptive maintenance policy to support the selection of optimal maintenance actions for a single component. Their paper also investigates the impact of imperfect maintenance actions. Lu et al. [19] presented an opportunistic maintenance approach for four main components of offshore wind turbines, where there are economic dependencies between components. The results show that the opportunistic maintenance strategy is efficient to reduce the maintenance cost.

In other fields of industry, Poppe et al. [20] combined three types of maintenance, condition-based maintenance, periodic preventive maintenance, and corrective maintenance, for the other components of the same vehicle system. Two maintenance thresholds are implemented on the degradation level to decide when to perform a maintenance action. The deterioration process is modeled utilizing continuous-time Markov chains. The multiple maintenance thresholds are optimized by Monte Carlo simulations. Zhu et al. [21] considered one opportunistic threshold and set the second threshold above the opportunis- 
tic threshold. He also monitored the degradation level of one component and presented a hybrid opportunistic maintenance policy that carries out condition-based maintenance on one critical component while proposing a corrective maintenance policy and preventive maintenance policy on the other components of the machine. The opportunistic maintenance threshold is optimized to minimize total maintenance cost through renewal theory. Therefore, determining maintenance threshold plays a vital step for achieving the optimal maintenance strategies.

Because of the remote nature of offshore wind systems, set-up cost for transportation and labor and cost due to production loss take up a significant proportion of the total maintenance cost [9]. Then, an optimal threshold of maintenance for the system must be determined carefully before making a maintenance schedule to avoid unnecessary maintenance activities and to minimize total maintenance cost. A wind system generally includes multiple wind turbines with multiple components, and each component has its own failure rate. Therefore, the optimization maintenance threshold should consider multiple components of multiple wind turbines instead of considering a single component or a single wind turbine. This research aims to propose an optimal maintenance threshold for an offshore wind power system to minimize maintenance cost while increasing system reliability. Various factors such as dynamic weather conditions, cost efficiency, system reliability, power loss during maintenance, maintenance duration, and market electricity price are considered carefully to enhance the reliability of the set-up model. The maintenance threshold could be applied for multiple components of multiple wind turbines in the system. Variable maintenance intervals are adopted to prevent an ineffective maintenance policy. Furthermore, the influence between components is considered in finding the maintenance threshold for the system where all main components are considered to enhance the system reliability. A two-stage procedure is proposed to obtain the expected maintenance threshold for the whole system where all main components are considered. A comprehensive valuable analysis model is conducted to evaluate its reliability and to contribute to a better understanding about maintenance policy.

The rest of this paper is arranged as follows. Section 2 reviews the research related to degradation model of wind turbine and fuzzy multi-objective programming. Section 3 focuses on model development to determine both individual component maintenance threshold and system maintenance threshold to optimize the maintenance policy for an offshore wind system. Section 4 illustrates various experiments and sensitivity analysis to assess the performance of the proposed model. Finally, Section 5 presents the conclusion and potential future work topics.

\section{Literature Review}

\subsection{Degradation of Wind Turbines}

The degradation and failure rates of the components of a wind turbine increase as the age of the components increases during the wind turbine's lifespan. According to Monga et al. [22], component $i$ is taken into account as a failure if the failure rate exceeds the failure threshold. Tuyet et al. [9] proposed that an offshore wind system is required to operate below the maximum allowable failure rate.

An offshore wind system is assumed to have $I$ components. The whole offshore wind system is temporarily shut down if there is a maintenance activity for any one component. In the study, the probability density function of the degradation coefficient of component $i$ is formulated by a two-parameter Weibull distribution

$$
f_{i}(t)=\frac{\omega}{\phi}\left(\frac{t}{\phi}\right)^{\omega-1} e^{-\left(\frac{t}{\phi}\right)^{\omega}}, i \in[1,2, \ldots, I]
$$


where $\phi$ and $\omega$ are the scale parameter and shape parameter, respectively. The mean $\left(E_{i}\right)$ and variance $\left(V_{i}\right)$ are given in Equations (2) and (3) respectively, where $\Gamma$ denotes the gamma function.

$$
\begin{gathered}
E_{i}=\phi \Gamma\left(1+\frac{1}{\omega}\right) \\
V_{i}=\phi^{2}\left[\Gamma\left(1+\frac{2}{\omega}\right)-\Gamma^{2}\left(1+\frac{1}{\omega}\right)\right]
\end{gathered}
$$

The mean time to failure (MTTF) is determined as the average expected time to failure for a non-repairable system and is calculated by Equation (4).

$$
\operatorname{MTTF}=\phi \Gamma\left(\frac{1}{\omega}+1\right)
$$

The Weibull failure rate function $\left(\psi_{i}(t)\right)$ of components $i$ representing the average number of failures is calculated by Equation (5).

$$
\psi_{i}(t)=\frac{f_{i}(t)}{r_{i}(t)}=\frac{\omega}{\phi}\left(\frac{t}{\phi}\right)^{\omega-1}
$$

Here $r_{i}(t)=e^{-(t / \phi)^{\omega}}$ denotes the component reliability when a component implements its intended function for a period of time $(t)$. The failure rate of an offshore wind turbine increases with a rise in a component's age. It means that $\psi_{i}(0)=0$ at $t=0$, $\psi_{i}(t+\Delta t)>\psi_{i}(t)$ and $\omega \geq 1$. When $\omega=1$, the failure rate of a component is a time constant, and the Weibull distribution is reduced to an exponential distribution, as displayed by Tuyet et al. [23]. The failure rate of each component $\psi_{i}(t)$ is utilized as short-term information in the model to determine the maintenance policy over a period of time.

\subsection{Review of Fuzzy Multi-Objective Programming}

There are three types of fuzzy programming including fuzzy flexible programming (FFP), fuzzy probabilistic programming (FPP), and robust programming (RP), as illustrated by Tsao et al. [24]. FFP solves problems with a flexible objective function and soft constraints. Nevertheless, problems with an uncertain coefficient in the objective function or constraints cannot be solved successfully by the method. RP may overcome the disadvantages of FFP by utilizing constraints with fuzzy numbers. Its main disadvantage is the assumption of uncertainty in a non-fuzzy decision space. FPP can achieve uncertain coefficients in the objective function and the constraints, as proposed by Pishvaee et al. [25]. FPP is often utilized to solve problems where the exact parameter values of the model cannot be determined.

According to the studies of [26-30], fuzzy techniques have been applied to general electrical system maintenance activities and to maintenance scheduling with the criteria of cost minimization, reliability maximization, and multi-objective. Zhong et al. [30] proposed a fuzzy multi-objective non-linear chance-constrained programming model to optimize the maintenance planning for offshore wind systems. A two-phase solution framework combining the operation rule for fuzzy arithmetic and the non-dominated sorting genetic algorithm II for multi-objective programming was conducted to solve the proposed problem. Fuzzy approaches have been utilized to solve other problems for wind farms. For instance, Zhong et al. [17] formulated a fuzzy multi-objective non-linear chanceconstrained programming model that proposed the new criteria of reliability and cost and the constraints to satisfy maintenance schedule for wind turbines. Siahkali et al. [31] solved the scheduling problem for wind farms by developing a fuzzy optimization-based approach. Wang et al. [32] proposed a bi-objective economic power dispatch model by examining wind penetration to minimize system risk and operation cost. Bahmani et al. [33] developed the multi-objective economic emission dispatch problem with minimal electric energy costs and emissions by combining wind generators. These results show that these 
proposed models are efficient to deal with the uncertainties in the piecewise generated power as fuzzy where the amount of power generation depends on the fuzzy offshore wind speed.

\section{Methodology}

\subsection{Solution Approach}

This research develops a mathematical model to independently determine the optimal maintenance threshold of individual components. The threshold is then utilized to determine the optimal maintenance threshold for a whole offshore wind system where all components are considered. The influence among components is carefully considered to obtain the optimal maintenance threshold for the whole system.

As shown in Figure 2, the optimal maintenance threshold for a component is calculated considering its maintenance cost and failure rate, which is determined through technical parameters and weather conditions in Taiwan where the wind turbine is installed. After determining the optimal maintenance threshold of an individual component, the optimal maintenance threshold for a system considering all components is obtained. The proposed approach is shown in Figure 2. The assumptions of the proposed approach are as follows.

1 The turbines of the offshore wind system are identical, and each component has its own independent deterioration process.

2 The system has to be shut down whenever there is a component under maintenance. The condition of components that are not maintained does not change during maintenance of other components.

3 A specific component is either the same for all wind turbines or with the same distribution of failures. Each component's failure rate has a Weibull distribution and is an increasing function of time.

4 Any component failure will be detected right away.

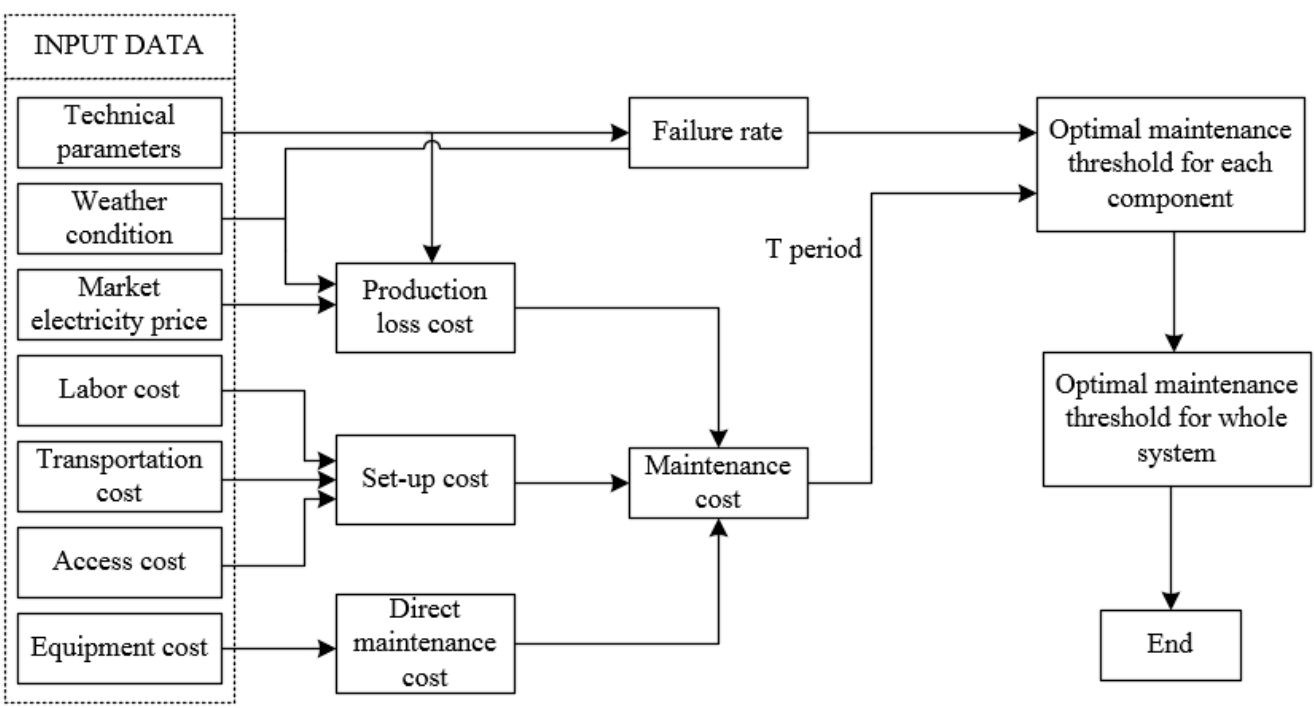

Figure 2. The proposed approach of maintenance policy optimization.

\subsection{Electricity Generation Model}

The generated electricity will be directly affected by technical parameters such as hub height, gearbox efficiency, generator efficiency, electrical efficiency, swept area of blades, and the wind turbine's power coefficient. Additionally, a number of environmental variables also influence the power generation of the system. When weather conditions prevent wind turbines from generating electricity, offshore wind systems will not become active. For instance, the offshore wind system will be in an inactive state to protect the wind system from damage under harsh weather conditions like typhoons or floods. When the wind speed is too fast or too slow, the offshore wind system will be set to an inactive 
state to ensure the wind system's safety. The wind turbine generates electricity only when the wind speed is between the cut-in speed and the cut-out speed $\left(V_{I} \leq v \leq V_{U}\right)$, and this period will not be counted toward the real utilization time. The offshore wind system will not generate electricity during the duration of maintenance. Therefore, the period also will not be counted into the real utilization time of the system. Consequently, the inactive periods of the system are not included into the real utilization time under practical generated electricity in the study of Tuyet et al. [9]. Nomenclatures used in the generated electricity model is showed in Table 1.

Table 1. Nomenclatures used in the generated electricity model.

\begin{tabular}{clcl}
\hline$P_{\text {loss }}$ & Electric loss $(\mathrm{W})$ & $C_{p}$ & Turbine power coefficient $(\%)$ \\
$p_{t}^{e}$ & Electric price (USD) & $h$ & Altitude above sea level $(\mathrm{m})$ \\
$T_{d}$ & Maintenance duration & $h_{r e f}$ & Reference height $(\mathrm{m})$ \\
$P_{p o}$ & Electric generated $\left(\mathrm{kg} / \mathrm{m}^{3}\right)$ & $z_{0}$ & Roughness length $(\mathrm{m})$ \\
$\rho$ & Air density $\left(\rho=1.25 \mathrm{~kg} / \mathrm{m}^{3}\right)$ & $G$ & Gas constant for air \\
$A$ & Rotor sweep area $\left(\mathrm{m}^{2}\right)$ & $T^{o}$ & Local air temperature $(\mathrm{K})$ \\
$v$ & Wind speed $(\mathrm{m} / \mathrm{s})$ & $g$ & Gravity constant $\left(9.81 \mathrm{~m} / \mathrm{s}^{2}\right)$ \\
$v_{r e f}$ & Wind speed at reference height & $\varphi$ & Local air pressure \\
$\gamma_{1}$ & Gearbox power coefficient & $R$ & Length of wind blades $(\mathrm{m})$ \\
$\gamma_{2}$ & Generator power coefficient & $P_{p a}$ & Aerodynamic power of \\
$\gamma_{3}$ & Electric power coefficient & & \\
\hline
\end{tabular}

The power output $\left(P_{p o}\right)$ transmitted to the grid from a wind turbine is calculated by

$$
P_{p o}=C_{p} \gamma_{1} \gamma_{2} \gamma_{3} P_{p a}
$$

where $P_{p a}$ is the aerodynamic power, $\gamma_{1}$ is the gearbox efficiency, $\gamma_{2}$ is the generator efficiency, $\gamma_{3}$ is the electric efficiency, and $C_{p}$ is the turbine power coefficient. The aerodynamic power $\left(P_{p a}\right)$ is proportional to the cube of wind speed $(v)$ at the blade swept area $(A)$, derived as:

$$
P_{p a}=\frac{1}{2} v^{3} A \rho=\frac{1}{2} v^{3} \pi R(R+2 r){\frac{\varphi}{G T^{o}}}^{\frac{-g h}{G T^{o}}}
$$

The blade swept area is quadrupled when the length of wind blades $(R)$ is doubled, because the blade swept area $\approx \pi R^{2}(R \gg 2 r)$. Furthermore, offshore wind power availability is affected by any slight change in wind speed, because the aerodynamic power is proportional to the cubed of the wind speed. However, wind speed is influenced by altitude change, and the height of the wind turbine hub $(h)$ and the roughness condition of the surface $\left(z_{0}\right)$ are required to measure the effects of altitude to wind speed. According to Hau et al. [34], the increase in wind speed with altitude is an increasing logarithmic function where the surface roughness $\left(z_{0}\right)$ of the sea is low relative to the land surface. The roughness of the offshore wind farm is dependent on the current wave field, which is dependent on the speed of the wind, the distance between the wind farm and the coast, the depth of water, and so on, as illustrated by Lange et al. [35]. Therefore, the power output of the turbine that can input to the grid is obtained through

$$
P_{p o}=\frac{1}{2} C_{p} \gamma_{1} \gamma_{2} \gamma_{3}\left(v_{r e f} \times \frac{\ln \frac{h}{z_{0}}}{\ln \frac{h_{r e f}}{z_{0}}}\right)^{3} \pi R(R+2 r){\frac{\varphi}{G T^{o}}}^{\frac{-g h}{G T^{o}}}
$$

We note that, for a pitch controlled wind turbine, the power coefficient of a turbine $\left(C_{p}\right)$ represents the turbine's efficiency of power conversion as a function of the speed ratio of the tip and the pitch angle of the blade pitch, as indicated by Blaabjerg et al. [36]. 
According to Tong et al. [37], the maximum power coefficient value is 0.593 , which is specified by the Betz's law, a fluid mechanics constraint. Therefore, Gasch et al. [38] said that only $59 \%$ of wind power could be used by a wind turbine based on Betz's law.

Based on Equation (8), the actual amount of energy that a wind turbine can convert into electricity depends on a turbine's hub height, blade swept area, and turbine efficiency. A system with a large swept area and a tall hub height can convert more energy from the environment. Wind speed increases lead to greater available energy. The wind speed can be calculated by using Equation (8), with wind speed at reference height $\left(v_{\text {ref }}\right)$ as the wind speed at $10 \mathrm{~m}$ above sea level. Wind speeds and weather conditions were obtained from the data collected by the Taiwanese government, and the maintenance policy was determined using the Weibull distribution. Actual electricity generated by an offshore wind system in Taiwan is used in this study.

\subsection{The First Stage: Maintenance Policy for a Component}

The first stage aims to determine the optimal maintenance threshold for individual components of the offshore wind power system. The maintenance threshold value ranges from 0 to 1 , in which the component will undergo maintenance frequency every month if the maintenance threshold is equal to 0 . It is extremely costly and unnecessary to change the maintenance frequency every month because the component failure rate following the technical specification is always greater than 0.5. Meanwhile, if the maintenance threshold value is equal to 1 , the component is in corrective maintenance which is performed after a fault in a component is detected to bring it back into the state where it can operate normally. Under corrective maintenance, the maintenance cost is lower, but the system reliability is worse. Therefore, obtaining the optimal maintenance threshold is essential to lower the cost of maintenance and enhance the reliability of the system.

Figure 3 demonstrates the maintenance optimization policy to find the optimal maintenance threshold for an individual component of a wind turbine that minimizes the maintenance cost $\left(C_{i}\right)$ for component $i$ n turbine $j$ under failure rate. $\left(\psi_{i}(t)\right)$. In the beginning, the maintenance threshold of the component $\left(\psi_{i, \text { threshold }}\right)$ and the failure rate of the component $\left(\psi_{i}\right)$ are set equal to 0 . The failure threshold $(L)$ is equal to 1 , in which the component is broken down. At time $t$, if the failure rate of the component $i\left(\psi_{i}(t)\right)$ is greater than the maintenance threshold $\left(\psi_{i, \text { threshold }}\right)$, component $i$ is maintained and the maintenance decision is decided at that time point. If the failure rate of the component $i\left(\psi_{i}(t)\right)$ is lower than the maintenance threshold $\left(\psi_{i, \text { threshold }}\right)$, the maintenance decision is not made at that time point. The cost of maintenance and the reliability of the system are calculated at that time point $(t)$. This process is repeated for the following epochs $(t-1, \ldots, 1)$. After finishing the above process, if the maintenance threshold value $\left(\psi_{i, \text { threshold }}\right)$ does not exceed the failure threshold $(L)$, then the maintenance threshold $\left(\psi_{i, \text { threshold }}\right)$ is added with $\sigma=0.001$. The maintenance decision process is repeated until the maintenance threshold value $\left(\psi_{i, \text { threshold }}\right)$ is equal to the failure threshold $(L)$. The same process is repeated for the other components of the system. The genetic algorithm is utilized to solve a dynamic strategy to determine the maintenance threshold of an individual component. 


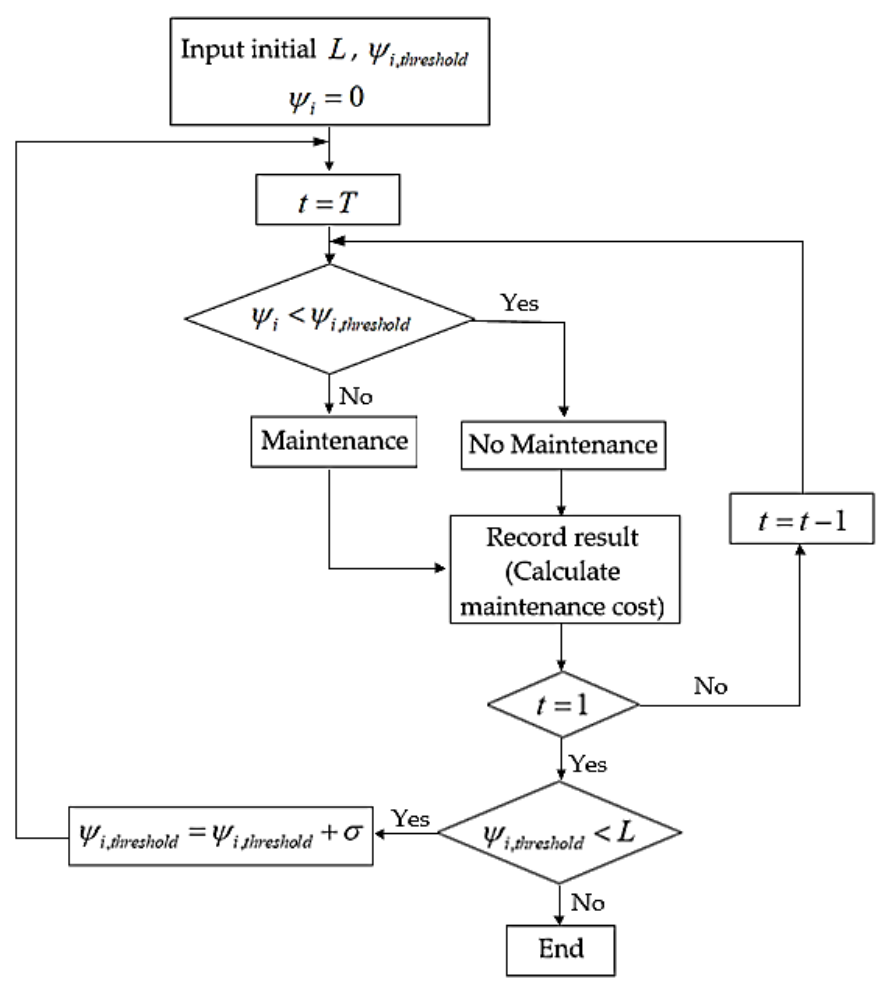

Figure 3. The proposed maintenance threshold of individual component optimization.

In order to determine the optimal threshold of a component, this study calculates the maintenance cost $\left(C_{i}\right)$ using Equation (9). In Equation (9), maintenance cost includes set-up cost $\left(C_{s}\right)$, equipment cost $\left(C_{e}\right)$, and production loss cost $\left(C_{l}\right)$ for $J$ wind turbines during $T$ periods.

The objective function is to minimize the maintenance cost of component of $J$ wind turbines during $T$ periods as given below:

$$
\begin{gathered}
C_{i}=\sum_{j=1}^{J} \sum_{t=1}^{T}\left(C_{s, t}(j)+C_{e, t}(j)+C_{l, t}(j)\right) \\
\min C\left(\psi_{\text {threshold }}\right)=\min \sum_{j=1}^{J} \sum_{t=1}^{T}\left(C_{s}+C_{e}+C_{l}\right) x_{j t}
\end{gathered}
$$

$x_{j t}= \begin{cases}1 & \text { If a component of wind turbine } j \text { is undergoing maintenance } \\ 0 & \text { Otherwise }\end{cases}$

The cost of production loss $\left(C_{l}\right)$ in Equation (9) denotes generated electricity $\left(P_{p o}\right)$ value during the maintenance duration $\left(T_{d}\right)$ according to the market price of electricity in year $t\left(P_{t}^{e}\right)$ and is given by:

$$
C_{l}=P_{p o} T_{d} P_{t}^{e}
$$

The generated electricity of the system $\left(P_{p o}\right)$ can be calculated through Equation (8) using the technical parameters and environmental conditions instead of the manufacturers' data. The technical parameters consist of the power coefficient $\left(C_{p}\right)$, gearbox efficiency, generator efficiency, electric efficiency $\left(\gamma_{1}, \gamma_{2}, \gamma_{3}\right)$, roughness length $\left(z_{0}\right)$, altitude above sea level $(h)$, reference height $\left(h_{r e f}\right)$, and length of wind blades $(R)$. The environmental condition includes gas constant for air $(G)$, gravity constant $(g)$, local air pressure $(\varphi)$, wind speed at reference height $\left(v_{\text {ref }}\right)$, and local air temperature $(T)$. 
From Equations (8)-(10), the optimal maintenance threshold of the individual maintenance of a wind system is obtained by using the genetic algorithm. The gene number of a maintenance threshold chromosome equals the number of considered components in wind the turbine. Each gene includes two-dimensional structures that encode the maintenance threshold of each component in the wind turbine. Each gene $\left(i, \psi_{i}\right)$ denotes the component (i) and maintenance threshold $\left(\psi_{i}\right)$ of this component. The maintenance threshold of each component ranges from 0 to 1 . The initial chromosome is filled with zeros. To assess the fitness, the resulting chromosome should satisfy the constraint $\left(\psi_{i, \text { threshold }}<L\right)$. Then, fitness should be assessed by utilizing the minimum maintenance cost function. The fitness value of each chromosome represents the minimum maintenance cost, and a lower value corresponds to higher fitness. The best chromosomes are selected for replication in the next generation to increase the solution quality. This is done by applying the roulette wheel method based on the relative fitness values. More specifically, the probability of selecting the parent $Z$ chromosome is calculated by

$$
p_{z}=\frac{\text { Objective value of } z}{\sum_{i=1}^{\text {Population size }}(\text { Objective value of } i)}
$$

A parent chromosome pair with higher probability will be chosen for single point crossover. After $\left(C_{i}\right)$ a gene is selected, a mutation selection process is done based on a predetermined mutation rate $(0.01 \%$ in this study). The minimum maintenance cost and number of maintenance activities of each component are calculated according to the optimal maintenance threshold of individual component. The cost $\left(C_{i}\right)$ includes the total maintenance cost of $J$ wind turbines during $T$ periods.

\subsection{The Second Stage: System's Maintenance Policy}

After determining the optimal maintenance threshold for an individual component, the second stage of the procedure consists of determining the maintenance threshold for whole system where all components are considered. The maintenance threshold of the whole offshore wind system is obtained by using fuzzy multi-objective programming. According to Pishvaee et al. [39], fuzzy multi-objective programming is among the best approaches for solving problems with uncertainty due to its capability of measuring and adjusting each objective function's satisfaction level. The second stage may be divided into the following steps:

Step 1: Convert the objective of component into an equivalent crisp model.

The objective (9) is transformed into an equivalent crisp model (13) by adjusting the objective function and constraints. The probability level of maintenance cost is given by trapezoidal fuzzy numbers $\left(\widetilde{p}_{c}=p_{c 1}, p_{c 2}, p_{c 3}, p_{c 4}\right)$.

$$
\min \sum_{i=1}^{I} C_{i}=\min \sum_{k=1}^{K} \widetilde{C}_{k} x_{k}^{\widetilde{\psi}_{k}}=\min \sum_{k=1}^{K}\left(C_{k 1}, C_{k 2}, C_{k 3}, C_{k 4}\right) x_{k}^{\widetilde{\psi}_{k}}
$$

Subject to:

$$
\sum_{k=1}^{K} \widetilde{\psi}_{k} x_{k}^{\widetilde{\psi}_{k}} \leq l_{k}, x_{k}^{\widetilde{\psi}_{k}}=[0,1]
$$

$x_{k}^{\widetilde{\psi}_{k}}= \begin{cases}1 & \text { If the components are maintained at a maintenance threshold } \widetilde{\psi}_{\mathrm{k}} \\ 0 & \text { Otherwise }\end{cases}$

Equation (13) presents the maintenance cost of $k$ th objective functions that is equivalent with $(i)$ components. Constraint (14) ensures that only one optimal maintenance threshold $\left(\widetilde{\psi}_{k}\right)$ is determined, and it does not exceed failure threshold $\left(l_{k}\right)$. In which failure threshold of components are given by trapezoidal fuzzy numbers $\left(l_{k}=l_{k 1}, l_{k 2}, l_{k 3}, l_{k 4}\right)$. Besides, 
the maintenance threshold of system is also presented by trapezoidal fuzzy numbers $\left(\widetilde{\psi}_{k}=\psi_{k 1}, \psi_{k 2}, \psi_{k 3}, \psi_{k 4}\right)$.

We introduce trapezoidal fuzzy numbers to deal with the constraints, such as $\left(\widetilde{a}_{i}=a_{i 1}, a_{i 2}, a_{i 3}, a_{i 4}\right)$ at each $\alpha-$ cut level interval $\left[(1-\alpha) a_{i 1}+\alpha a_{i 2} ;(1-\alpha) a_{i 4}+\alpha a_{i 3}\right]$ for lower and upper bounds of the objective functions and constraints. The $\alpha-$ cut level is defined as a set of elements in a fuzzy set whose membership grade is greater or equal to $\alpha$ [24]. Then we can directly convert Equation (9) into two sub-models that fit the objective's and constraints' upper and lower bounds with $\alpha-c u t$ as follows:

1. Lower sub-model

$$
\min C=\sum_{k=1}^{K}\left[(1-\alpha) C_{k 1}+\alpha C_{k 2}\right] x_{k}^{\widetilde{\psi}_{k}}
$$

Constraints:

$$
\begin{gathered}
\sum_{k=1}^{K}\left[(1-\alpha) \psi_{k 1}+\alpha \psi_{k 2}\right] x_{k}^{\widetilde{\psi}_{k}} \leq(1-\alpha) l_{k 1}+\alpha l_{k 2} \\
x_{k}^{\widetilde{\psi}_{k}} \geq 0
\end{gathered}
$$

2. Upper sub-model

$$
\min C=\sum_{k=1}^{K}\left[(1-\alpha) C_{k 4}+\alpha C_{k 3}\right] x_{k}^{\widetilde{\psi}_{k}}
$$

Constraints:

$$
\begin{gathered}
\sum_{k=1}^{K}\left[(1-\alpha) \psi_{k 4}+\alpha \psi_{k 3}\right] x_{k}^{\widetilde{\psi}_{k}} \leq(1-\alpha) l_{k 4}+\alpha l_{k 3} \\
x_{k}^{\widetilde{\psi}_{k}} \geq 0
\end{gathered}
$$

Step 2: The $\alpha$ - positive value $(\alpha-P O)$ is obtained in the first step that is to determine the maintenance threshold for an individual maintenance threshold. The $\alpha-n e g a t i v e$ ideal solution $(\alpha-N E)$ for each objective function is determined with lower and upper bounds as:

$$
C_{1,2,3,4}^{N E-l}=C_{1,2,3,4}^{P O-l}\left(x_{1,2,3,4}^{P O-l}\right), C_{1,2,3,4}^{N E-u}=C_{1,2,3,4}^{P O-u}\left(x_{1,2,3,4}^{P O-u}\right)
$$

This region is feasible for each of the objective functions.

$$
C_{k}=\left[\left(C_{k}^{P O-l} ; C_{k}^{N E-l}\right) ;\left(C_{k}^{P O-u} ; C_{k}^{N E-u}\right)\right], k=1,2,3,4
$$

Step 3: Obtain each objective function's linear membership function.

$$
\begin{gathered}
\mu_{\left(C_{k}\right)}^{l}(v)=\left\{\begin{array}{cl}
1 & C_{k}^{l} \leq C_{k}^{P O-l} \\
\frac{C_{k}^{N E-l}-C_{k}^{l}}{C_{k}^{N E-l}-C_{k}^{P O-l}} & C_{k}^{P O-l}<C_{k}^{l}<C_{k}^{N E-l}, k=1,2,3,4 \\
0 & C_{k}^{l}>C_{k}^{N E-l}
\end{array}\right. \\
\mu_{\left(C_{k}\right)}^{u}(v)=\left\{\begin{array}{cl}
1 & C_{k}^{u} \leq C_{k}^{P O-u} \\
\frac{C_{k}^{N E-u}-C_{k}^{u}}{C_{k}^{N E-u}-C_{k}^{P O-u}} & C_{k}^{P O-u}<C_{k}^{u}<C_{k}^{N E-u}, k=1,2,3,4 \\
0 & C_{k}^{u}>C_{k}^{N E-u}
\end{array}\right.
\end{gathered}
$$

In which, $\mu_{\left(C_{k}\right)}^{l, u}(v)$ denotes the lower bound and upper bound of the satisfaction degree of the $k$ th objective for any solution $v$ to the sub-models.

Step 4: Generate a single objective model from the equivalent crisp. 
Use the TH aggregation function [40] to generate a single-objective model based on the equivalent crisp model by the following model.

$$
\begin{gathered}
\operatorname{Max} \theta(x)=\eta \theta_{0}+(1-\eta) \sum_{k=1,2,3,4} v_{C_{k}} \mu_{C_{k}}(x) \\
\text { S.t. } \theta_{0} \leq \mu_{C_{k}}(x), k=1,2,3,4, x \in F(x), \theta_{0}, \eta \in[0,1]
\end{gathered}
$$

where

$\mu_{C_{k}}(x)$ : is the linear membership function representing the satisfaction degree of $k$ th objective function,

$\theta_{0}=\min _{C_{k}}\left\{\mu_{C_{k}}(x)\right\}:$ is the minimum satisfaction degree of objective functions,

$v_{C_{k}}$ : is the importance of the $k$ th objective function (betwen 0 and 1), and

$\eta$ : is the coefficient of compensation (between 0 and 1 ).

Step 5: Determine the compensation coefficient $\eta$ and the fuzzy goal of relative importance $v_{C_{k}}$.

Step 6: Utilize the lower and upper sub-models to solve the single-objective models. Then the following solution can be obtained.

$$
K_{i}^{l, u}=\left(k_{i}^{l}, k_{i}^{u}\right),(i=1, \ldots, n)
$$

Change the value of a controllable parameter ( $\alpha-$ cut level or $\eta$ ) to obtain another solution. Return to step 1 (dealing with constraints).

\section{Numerical Analysis}

\subsection{Input Data}

This study considers three Vestas V90-3 MW offshore wind turbines in an offshore wind system that consist of four main components. The data is adopted from Tuyet et al. [23] and Zhang et al. [41]. According to Tuyet et al. [23], the turbine is lightweight with high portability and low foundation costs. Its detailed specifications are highlighted in Table 2 [42].

Table 2. The technical parameters of Vestas V90-3 MW.

\begin{tabular}{ll}
\hline Technical Specifications & Vestas V90-3 MW \\
\hline Operation data & \\
Rated power & $300 \mathrm{~kW}$ \\
Cut-in wind speed & $3.5 \mathrm{~m} / \mathrm{s}$ \\
$\quad$ Cut-out wind speed & $25 \mathrm{~m} / \mathrm{s}$ \\
$\quad$ Operating temperature range of standard turbine & $-20^{\circ} \mathrm{C}$ to $40^{\circ} \mathrm{C}$ \\
Rotor & \\
$\quad$ Rotor diameter & $90 \mathrm{~m}$ \\
$\quad$ Swept area & $6362 \mathrm{~m}^{2}$ \\
$\quad$ Rotor nominal revolutions & $16.1 \mathrm{rpm}$ \\
$\quad$ Operational interval & $8.6-18.4 \mathrm{rpm}$ \\
Tower & \\
$\quad$ Hub height & $80 \mathrm{~m}$ \\
Nacelle dimensions & \\
Height for transport & $4 \mathrm{~m}$ \\
$\quad$ Length & $9.65 \mathrm{~m}$ \\
Width & $3.65 \mathrm{~m}$ \\
Hub dimensions & \\
Max. transport height & $3.6 \mathrm{~m}$ \\
Max. transport width & $4.2 \mathrm{~m}$ \\
Max. transport length & $4.4 \mathrm{~m}$ \\
\hline
\end{tabular}


Table 2. Cont.

\begin{tabular}{ll}
\hline Technical Specifications & Vestas V90-3 MW \\
\hline Blade dimensions & \\
Length & 44 \\
Max. chord & 3.5 \\
Max. weight per unit for transportation & 70 tones \\
\hline
\end{tabular}

According to Tuyet et al. [23], the offshore wind turbine's total lifespan is 20 years or 240 months $(T=240)$. The turbine's cost is USD $1453 / \mathrm{kW}$, and the cost of foundations, installation, and electrical infrastructure is USD 2698/ kW. The capital cost of the offshore wind system is USD $4150 / \mathrm{kW}$. The labor cost in Taiwan is USD 132/day/person, and the required labor is 3 people per maintenance activity. The transportation cost includes the costs of cranes and drivers, which is USD 487 for every maintenance activity.

The four main components of an offshore wind system are the rotor system, bearing, generator, and gearbox. The failure rate of the component is simulated [41]. The shape parameter and scale parameter of the component are obtained from Zhang et al. [41]. Table 3 lists the cost data of the main components.

Table 3. The parameters of the four main components.

\begin{tabular}{cccc}
\hline $\begin{array}{c}\text { Major } \\
\text { Components }\end{array}$ & $\begin{array}{c}\text { Scale Parameter } \\
(\boldsymbol{\phi})\end{array}$ & $\begin{array}{c}\text { Shape Parameter } \\
(\boldsymbol{\omega})\end{array}$ & $\begin{array}{c}\text { Component Cost } \\
\text { Sharing }\end{array}$ \\
\hline Rotor system & 3000 & 3 & $22.20 \%$ \\
Bearing & 3750 & 2 & $1.22 \%$ \\
Gearbox & 2400 & 3 & $14.91 \%$ \\
Generator & 3300 & 2 & $8.44 \%$ \\
\hline
\end{tabular}

\subsection{The First Stage: Maintenance Policy for a Component}

The optimal maintenance threshold of an individual component is obtained by using a genetic algorithm to solve the dynamic maintenance strategy. The result of the proposed maintenance policy for each component in Table 4 indicates that an offshore wind system's maintenance threshold and the total cost of maintenance is dependent on the scale parameter, the shape parameter of each component, and weather conditions.

Table 4. The parameters and maintenance costs of components.

\begin{tabular}{cccc}
\hline Components & $\begin{array}{c}\text { Maintenance } \\
\text { Threshold } \\
\left(\psi_{i, \text { threshold })}\right)\end{array}$ & $\begin{array}{c}\text { System Reliability (\%) } \\
\left(\boldsymbol{R}_{s}\right)\end{array}$ & $\begin{array}{c}\text { Maintenance Cost } \\
\text { (USD) } \\
\left(\boldsymbol{C}\left(\psi_{i, \text { threshold }}\right)\right)\end{array}$ \\
\hline Rotor system & 0.9784 & 97.01 & 202,791 \\
Bearing & 0.9614 & 95.21 & 228,140 \\
Gearbox & 0.9637 & 96.82 & 228,140 \\
Generator & 0.9801 & 94.08 & 126,744 \\
\hline
\end{tabular}

Table 4 illustrates that with the highest maintenance threshold (0.9801), a generator achieves the lowest maintenance cost (USD 126,744) and system reliability $(94.08 \%)$ if compared with the results of rotor system, bearing, and gearbox. Moreover, a bearing has the lowest maintenance threshold with 0.9614 that leads to the highest maintenance cost of USD 228,140. We also see that the maintenance threshold significantly impacts the total maintenance cost which increases the maintenance threshold, which then leads to a drop in the maintenance cost. However, system reliability goes down if the maintenance threshold rises. 
Each component has its own failure rate. Based on the maintenance threshold of each component, the total number of maintenance activities for each component are determined differently and shown in Table 5.

Table 5. Component's maintenance frequency in 240 months.

\begin{tabular}{cc}
\hline Components & Number of Maintenance Activities \\
\hline Rotor system & 3 \\
Bearing & 12 \\
Generator & 15 \\
Gearbox & 6 \\
Total maintenance activities & 36 \\
\hline
\end{tabular}

\subsection{The Second Stage: Maintenance Policy for a System}

After determining the maintenance threshold for each component, the maintenance threshold for the system with all four main components is obtained by using the fuzzy multi-objective model. The data inputs include the maintenance threshold, the failure rate, the total maintenance cost, equipment cost, set-up cost, and the production loss cost of a component, which are determined by optimizing the maintenance policy for an individual component.

Table 6 presents the optimal maintenance threshold, maintenance cost, and reliability of an offshore wind system. The table illustrates the main results for the variety of $\alpha-c u t$ levels, consisting of objective values, degree of satisfaction, maintenance threshold, and system reliability. From Table 6 and Figure 4, the average maintenance cost increases from USD 188,674 to USD 226,013 at an average maintenance threshold decreasing from $\psi_{s, \text { threshold }}=0.9944$ to $\psi_{s, \text { threshold }}=0.9715$, thus increasing the average offshore system reliability from $96.32 \%$ to $98.40 \%$, respectively.

Table 6. Summary of experimental results.

\begin{tabular}{ccccc}
\hline $\boldsymbol{\alpha}$-Cut Level & $\begin{array}{c}\text { Objective Function Value } \\
\left(\boldsymbol{C}_{\boldsymbol{s}}\right)\end{array}$ & $\begin{array}{c}\text { The Satisfaction } \\
\text { Degree } \\
\left(\boldsymbol{\mu}_{\left.\boldsymbol{C}_{s}\right)}\right.\end{array}$ & $\begin{array}{c}\text { Maintenance } \\
\text { Threshold } \\
\boldsymbol{\psi}_{s, \text { threshold }}\end{array}$ & $\begin{array}{c}\text { System Reliability } \\
\left(\boldsymbol{R}_{\boldsymbol{s}}\right)\end{array}$ \\
\hline 0.1 & $(176,651.49,200,696.88)$ & $(0.82,0.88)$ & $(0.9891,0.9996)$ & $(95.8290,96.8091)$ \\
0.2 & $(189,666.19,208,711.76)$ & $(0.76,0.87)$ & $(0.9879,0.9973)$ & $(96.0489,96.9858)$ \\
0.3 & $(191,668.24,215,714.65)$ & $(0.80,0.94)$ & $(0.9860,0.9942)$ & $(96.6392,97.0483)$ \\
0.4 & $(197,682.64,219,202.55)$ & $(0.81,0.90)$ & $(0.9849,0.9925)$ & $(96.6027,97.3667)$ \\
0.5 & $(200,699.94,224,637.15)$ & $(0.78,0.88)$ & $(0.9777,0.9884)$ & $(96.8669,97.9364)$ \\
0.6 & $(200,948.44,224,692.95)$ & $(0.78,0.88)$ & $(0.9772,0.9866)$ & $(97.0270,97.9658)$ \\
0.7 & $(201,752.14,224,943.52)$ & $(0.86,0.96)$ & $(0.9709,0.9818)$ & $(97.3956,98.4871)$ \\
0.8 & $(211,878.04,225,286.35)$ & $(0.86,0.94)$ & $(0.9707,0.9780)$ & $(97.7982,98.5316)$ \\
0.9 & $(212,930.84,228,988.05)$ & $(0.82,0.94)$ & $(0.9689,0.9770)$ & $(97.8413,98.6546)$ \\
1.0 & $(219,401.64,232,624.85)$ & $(0.74,0.81)$ & $(0.9672,0.9757)$ & $(97.9758,98.8214)$ \\
\hline
\end{tabular}

\subsection{Sensitivity Analysis}

Sensitivity analysis is performed with an $\alpha-$ cut level from 0.1 to 1.0. The study utilizes four weight vectors $v_{c_{1}}=0.1, v_{c_{2}}=0.3, v_{c_{3}}=0.4$, and $v_{c_{4}}=0.2$ along with the compensation coefficient $\eta=0.6$ to test the problem. As shown in Table 6 , the optimal maintenance threshold and the maintenance cost for the objective function are sensitive to the $\alpha-c u t$ level, tending to increase with the $\alpha-c u t$ values. Therefore, the decision makers (DMs) should choose a high maintenance threshold to achieve a low maintenance cost. However, in order to achieve high system reliability, the maintenance threshold should be lower. The minimum acceptable value may vary according to the selection of the DMs after each iteration. 


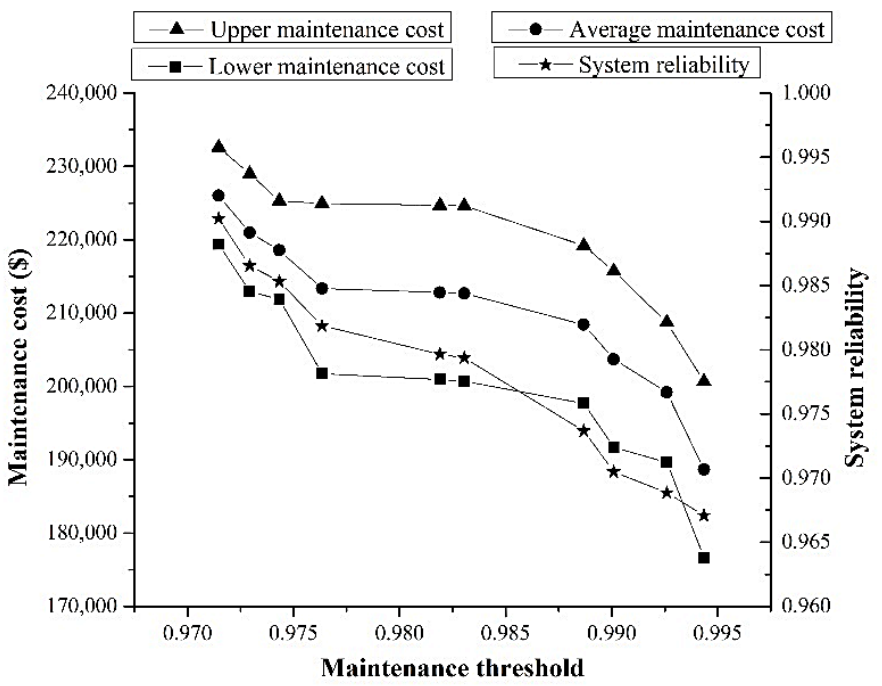

Figure 4. Maintenance cost and system reliability as a function of maintenance threshold.

As can be seen in the results of Table 6 , at $\alpha=0.1$ the optimal maintenance cost is the lowest, ranging from USD 176,651 to USD 200,696 when the optimal maintenance threshold of the system is from 0.9891 to 0.9996 that leads to the lowest wind system reliability $R_{s}=(95.8290,96.8091)$ and degree of satisfaction $\mu_{C_{s}}=(0.82,0.88)$. The maximum degree of satisfaction in the objective function $\mu_{C_{s}}=(0.86,0.96)$ is achieved at $\alpha=0.7$. The optimal maintenance threshold of the system $\left(\psi_{s, t h r e s h o l d}\right)$ runs from 0.9709 to 0.9818 , in which the optimal maintenance cost is $5.57 \%$ higher than the number at $\alpha=0.1$. However, at $\alpha=0.7$ the offshore wind system's reliability is $7.06 \%$ higher than the figure at $\alpha=0.1$. The maximize offshore wind system reliability at $97.98 \%$ to $98.82 \%$ is obtained when $\alpha=1$ under maintenance threshold ranging from 0.9672 to 0.9757 . However, the degree of satisfaction of the objective function at $\alpha=1$ is the lowest, ranging from $74 \%$ to $81 \%$. Additionally, the total maintenance cost is the highest ranging from USD 219,401 to USD 232,624 in comparison with other values at different $\alpha-$ cut levels.

Figure 5 presents the change in the upper and lower satisfaction degrees in relation to the objective functions. The DMs express varying degrees of confidence under uncertain situations. Therefore, at $\alpha=0.7$ the satisfaction level is the highest and the resulting solution is most balanced.

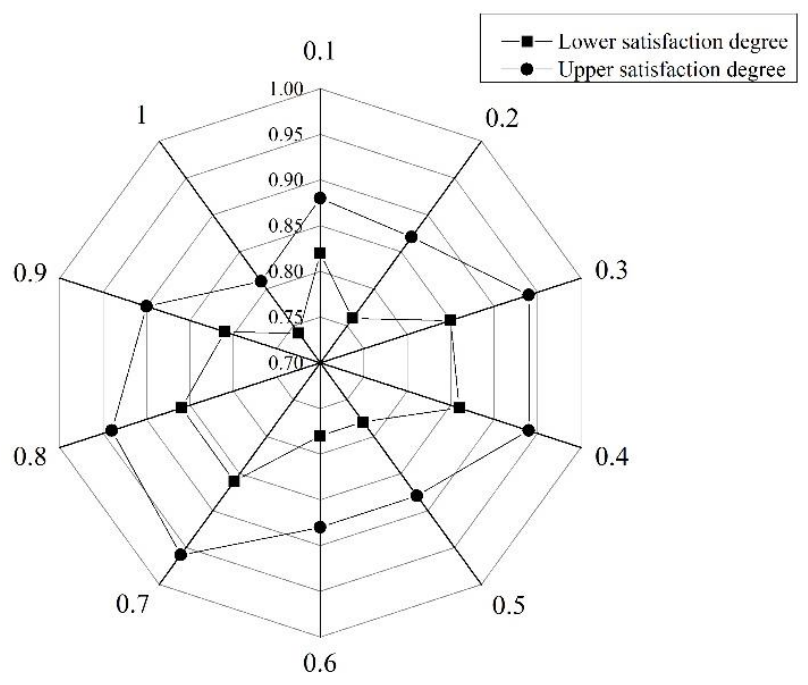

Figure 5. Illustration of the relationship between satisfaction degrees and confidence levels. 


\subsection{Performance Evaluation}

To evaluate the proposed model's performance, we utilize the average maintenance threshold of the whole system $\left(\psi_{s, \text { threshold }}=0.9763\right)$ that obtains the highest overall satisfaction degree of the objective function to determine the total number of maintenance activities and maintenance cost. Then, a comparison is made between the determined maintenance policy for the whole system considering four main components and the individual component policy.

From the results in Tables 7 and 8, the total number of maintenance activities of the whole wind system is 36 times at the maintenance threshold $\left(\psi_{s, t h r e s h o l d}=0.9763\right)$, resulting in a total maintenance cost of USD 206,088 and increasing the reliability of the offshore wind system to $98.16 \%$.

Table 7. The parameters and maintenance cost of the offshore wind system.

\begin{tabular}{ccc}
\hline $\begin{array}{c}\text { Maintenance Threshold } \\
\left(\psi_{s, \text { threshold }}\right)\end{array}$ & $\begin{array}{c}\text { Maintenance Cost (USD) } \\
\left(\boldsymbol{C}\left(\psi_{s, \text { threshold })}\right)\right.\end{array}$ & $\begin{array}{c}\text { System Reliability (\%) } \\
\left(\boldsymbol{R}_{s}\right)\end{array}$ \\
\hline 0.9763 & 206,088 & 98.16 \\
\hline
\end{tabular}

Table 8. The optimal total number of maintenance activities for the whole system for 240 months.

\begin{tabular}{cc}
\hline Components & Number of Maintenance Activities \\
\hline Rotor system & 3 \\
Bearing & 10 \\
Generator & 12 \\
Gearbox & 11 \\
Total maintenance activities & 36 \\
\hline
\end{tabular}

The result shows that the maintenance policy for the whole system considering all four main components is more effective than the maintenance policy for the individual components. Figures 6 and 7 show that, during the 240-month period, the generator maintenance policy achieves the lowest maintenance cost of USD 126,740 at the maintenance threshold $\left(\psi_{4, \text { threshold }}=0.9801\right)$. However, the system reliability is the lowest at $94.08 \%$ compared to the other maintenance policies. On the other hand, if the system follows the rotor system maintenance policy at the maintenance threshold $\left(\psi_{1, \text { thrershold }}=0.9784\right)$, the system reliability increases by $3.11 \%$, but the maintenance cost rises significantly by $60 \%$. The same is true for the bearing and gearbox maintenance strategies.

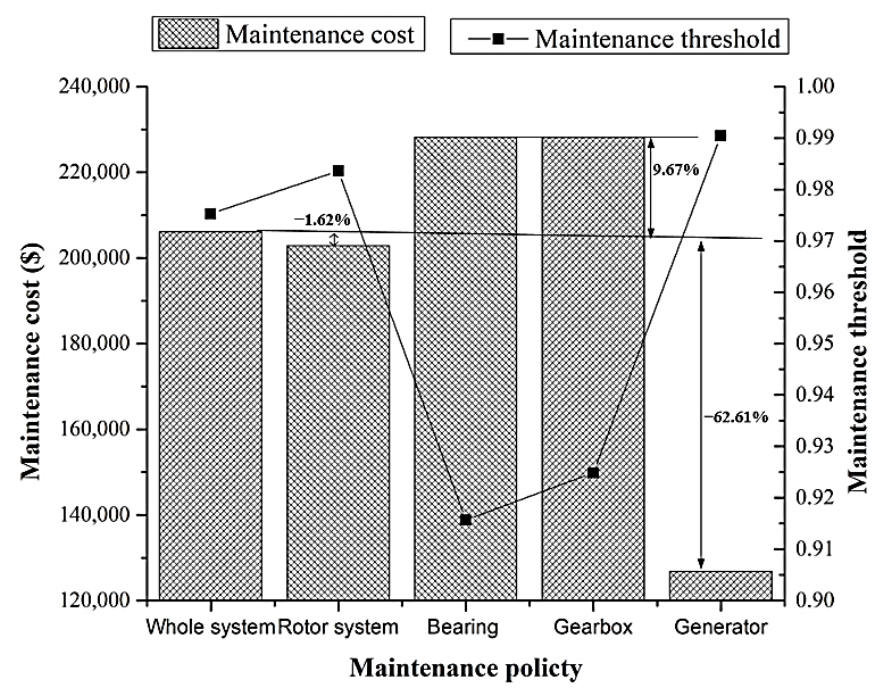

Figure 6. The maintenance cost as a function of maintenance threshold comparison. 


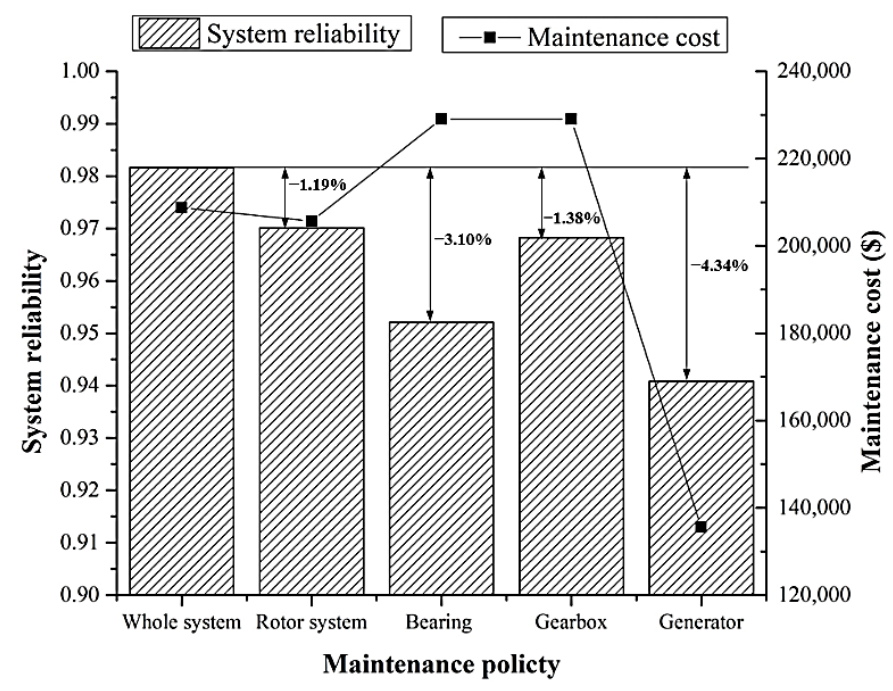

Figure 7. The maintenance cost as a function of system reliability comparison.

In contrast, the reliability of the offshore wind system increases to $98.18 \%$ when the system maintenance policy is applied to the optimal maintenance threshold $\left(\psi_{s, t h r e s h o l d}=0.9763\right)$, where the optimal maintenance cost is USD 206,088. The result means that the system's reliability and maintenance cost increase by approximately $1.19 \%$ and $1.62 \%$, respectively, when compared with the maintenance policy of the rotor system during the maintenance period. The increasing discrepancy between the total maintenance cost and system reliability is more acceptable and reasonable for the whole wind power system maintenance policy than for the individual maintenance policies.

The whole-system maintenance policy which considers all four main components is more efficient and reliable than the maintenance policy for individual components. Since each component has its own failure rate, the total maintenance cost and system reliability may not be satisfied simultaneously if the whole system maintenance activity is designed using the respective threshold for single component maintenance. In contrast, both the total maintenance cost and system reliability factors can be satisfied with the maintenance policy of the whole system where all four main components are considered in this study.

Our numerical experiments offer several insights for management. If the DMs exhibit a higher confidence level when facing uncertainty, they can accept a lower maintenance threshold and spend slightly more on maintenance costs to ensure better system reliability. Second, the lowest maintenance cost can be achieved, but at the expense of system reliability. Therefore, DMs should consider a benchmark for the maintenance policy of the whole offshore wind system that accounts for the maintenance cost and the targeted reliability benchmark to determine a balanced solution with multi-objective functions.

\section{Conclusions}

In this study, an efficient maintenance policy with an optimal maintenance threshold for the whole system is proposed to enhance the cost effectiveness of an offshore wind system. In determining the optimal maintenance threshold that minimizes the overall cost of maintenance and increases the reliability of the system, several factors including reliability, cost effectiveness, conditions of weather, duration of maintenance, losses of power generation due to maintenance, and market price of electricity are considered. We developed a two-stage procedure to determine the optimal solution.

The results indicate that a system's maintenance policy considering all components can achieve optimal maintenance cost and increase system reliability better than a maintenance policy only for the individual components. Additionally, the increasing discrepancy between maintenance cost and system reliability is more appropriate with system maintenance policy. Moreover, the numerical analyses show the potential of the proposed approach as it helps to solve a multi-objective problem under uncertainty parameters, thus 
providing a more balanced solution. Care must be taken when applying the proposed approach because it depends on the DM's preferences of parameters.

There are some possible developments for further research. First, resource constraints such as labor, transportation, and material can be studied as a possible extension to improve the reliability of the model. Second, the routing problem can be considered to find the optimal strategy for the maintenance of offshore wind turbines. Finally, after maintenance, a component is not always restored to the same condition as before because the failure rate increases with the age of the component. Therefore, imperfect and perfect maintenance policies for several components of wind turbines could be considered for research extension.

Author Contributions: Conceptualization, V.F.Y. and T.H.A.L.; data curation, T.H.A.L.; formal analysis, T.H.A.L.; funding acquisition, V.F.Y. and S.-W.L.; investigation, T.H.A.L.; methodology, T.H.A.L.; project administration, V.F.Y.; resources, V.F.Y. and T.H.A.L.; software, T.H.A.L.; supervision, V.F.Y., T.-S.S. and S.-W.L.; validation, V.F.Y., T.H.A.L. and S.-W.L.; visualization, T.H.A.L.; writing-original draft preparation, T.H.A.L.; writing-review and editing, V.F.Y., T.H.A.L., T.-S.S. and S.-W.L. All authors have read and agreed to the published version of the manuscript.

Funding: The work of the first author and the third author is partially supported by the National Taiwan University of Science and Technology and National Pingtung University of Science and Technology under Grant NPUST-NYUST-NTUST-109-07. The work of the first author is also financially supported in part by the Center for Cyber-Physical System Innovation from The Featured Areas Research Center Program within the framework of the Higher Education Sprout Project by the Ministry of Education (MOE) in Taiwan. The work of the second author is supported by The University of Danang, University of Science and Technology (Code Number of Project: T2020-02-17). The work of the fourth author is supported in part by the Ministry of Science and Technology, Taiwan, under Grant MOST 109-2410-H-182-009MY3, and in part by the Linkou Chang Gung Memorial Hospital under Grant BMRPA19.

Institutional Review Board Statement: Not applicable.

Informed Consent Statement: Not applicable.

Data Availability Statement: Not applicable.

Conflicts of Interest: The authors declare no conflict of interest.

\section{References}

1. Global Wind Energy Council (GWEC). Global Wind Report 2021. Available online: gwec.net (accessed on 25 March 2021).

2. Jiang, Z. Installation of offshore win turbines: A technical review. Renew. Sustain. Energy Rev. 2021, 139, 161-176. [CrossRef]

3. Wu, X.; Yu, H.; Li, Y.; Yang, J.; Lei, D.; Wang, T.; Thomas, A.; Jiang, Z.; Zhen, G.; Lin, Z.; et al. Foundations of offshore wind turbines: A review. Renew. Sustain. Energy Rev. 2019, 104, 379-393. [CrossRef]

4. Lin, Z.; Cevasco, D.; Collu, M. A methodology to develop reduced-order models to support the operation and maintenance of offshore wind turbines. Appl. Energy 2020, 259, 114228. [CrossRef]

5. Tyler, J.S.; Beiter, P.C. Cost of Wind Energy Review; National Renewable Energy Lab (NREL): Golden, CO, USA, 2020.

6. Ren, Z.; Verma, A.S.; Li, Y.; Teuwen, J.J.E.; Jiang, Z. Offshore wind turbine operations and maintenance: A state-of-the-art review. Renew. Sustain. Energy Rev. 2021, 144, 110886. [CrossRef]

7. Panneerselvam, R. Production and Operations Management; PHI Learning Pvt. Ltd.: Delhi, India, 2012.

8. Kerres, F.; Madlener. Economic evaluation of maintenance strategies for wind turbines: A stochastic analysis. Iet. Renew. Power Gener. 2015, 9, 766-774. [CrossRef]

9. Tuyet, N.T.A. Economic Feasibility Study for Supporting Renewable Energy Adoption; National Taiwan University of Science and Technology: Taipei, Taiwan, 2018.

10. Bagshaw, K.B. A review and analysis of plant maintenance and replacement strategies of manufacturing firms in Nigeria. Afr. J. Bus. Manag. 2017, 11, 17-26.

11. Chen, A.; Wei, G.; Tao, Y.; Sheng, G. Opportunistic maintenance strategy for wind turbine considering weather conditions and spare parts inventory management. Renew. Energy 2019, 109, 1-9.

12. Kang, J.; Soares, G.G. An opportunistic maintenance policy for offshore wind farms. Ocean. Eng. 2020, 216, 108075. [CrossRef]

13. Rander, D.W.J. Opportunistic maintenance of a single part in the presence of several monitored parts. Manag. Sci. 1963, 10, 70-84.

14. Mccall, J.J. Operating Characteristics of Opportunistic Replacement and Inspection Policies. Manag. Sci. 1963, 10, 85-97. [CrossRef] 
15. Zhou, X.L. Opportunistics preventive maintenance scheduling for multi-unit series system based on dynamic programming. Int. J. Prod. Econ. 2009, 118, 361-366. [CrossRef]

16. Di, L.Y. Optimal preventive maintenance model based on opportunistic maintenance policy. Chin. J. Eng. Des. 2012, 19, 263-267.

17. Zhong, P.; Beer, Z. Constrained non-linear multi-objective optimisation of preventive maintenance scheduling for offshore wind farms. Mech. Syst. Signal. Process. 2018, 104, 347-369. [CrossRef]

18. Do, P.; Voisin, A.; Levrat, E.; Iung, B. A proactive condition-based maintenance strategy with both perfect and imperfect maintenance actions. Reliab. Eng. Syst. Saf. 2015, 133, 22-32. [CrossRef]

19. Yang, L.; Zhang, X.; Feng, F.; Kang, J.; Fu, G. Condition based maintenance optimization for offshore wind turbine considering opportunistics based on neural network approach. Appl. Ocean. Res. 2018, 74, 69-79.

20. Poppe, J.; Boute, R.N.; Lambrecht, M.R. A hybrid condition-based maintenance policy for continuously monitored components with two degradation thresholds. Eur. J. Oper. Res. 2018, 268, 515-532. [CrossRef]

21. Zhu, Q.P.; Timmermans, B.; van Houtum, G.-J. A condition-based mainetenacne model for single component in a system with scheduled and unscheduled downs. Int. J. Prod. Econ. 2017, 193, 39. [CrossRef]

22. Monga, A.; Zuo, M.J. Optimal design of series-parallel systems considering maintenance and salvage value. Comput. Ind. Eng. 2001, 40, 323-337. [CrossRef]

23. Tuyet, N.T.A.; Chou, S.Y. Maintenance strategy selection for improving cost-effectiveness of offshore wind systems. Energy Convers. Manag. 2018, 157, 86-95. [CrossRef]

24. Tsao, T.; Lu, Y. Designing sustainable supply chain networks under uncertain environments: Fuzzy multi-objective programming. J. Clean. Prod. 2018, 174, 1550-1565. [CrossRef]

25. Pishvaee, M.S.; Khalaf, M.F. Novel robust fuzzy mathematical programming methods. Appl. Math. Model. 2016, 40, 407-418. [CrossRef]

26. El-Sharkh, M.Y.; El-Keib, A.A.; Chen, H. A fuzzy evolutionary programming-based solution methodology for security-constrained generation maintenance scheduling. Electr. Pow. Syst. Res. 2003, 67, 67-72. [CrossRef]

27. Sergaki, A.; Kalaitzakis, K. A fuzzy knowledge based method for maintenance planning in a power system. Reliab. Eng. Syst. Saf. 2002, 77, 19-30. [CrossRef]

28. Volkanovski, A.; Mavko, B.; Bosevski, T.; Causevski, A.; Cepin, M. Genetic algorithm optimisation of the maintenance scheduling of generating units in a power system. Reliab. Eng. Syst. Saf. 2008, 93, 779-789. [CrossRef]

29. Liu, Y.L.; Huang, M.J.; Zuo, Z.S. Optimal preventive maintenance policy under fuzzy Bayesian reliability assessment environments. IIE Trans. 2010, 42, 734-745. [CrossRef]

30. Zhong, S.; Pantelous, A.A.; Goh, M.; Zhou, J. A reliability-and-cost-based fuzzy approach to optimize preventive maintenance scheduling for offshore wind farms. Mech. Syst. Signal. Process. 2019, 124, 643-663. [CrossRef]

31. Siahkali, H.; Vakilian, M. Fuzzy generation scheduling for a generation company (GenCo) with large scale wind farms. Energy Convers. Manag. 2010, 51, 1947-1957. [CrossRef]

32. Wang, L.; Singh, C. Balancing risk and cost in fuzzy economic dispatch including wind power penetration based on particle swarm optimization. Electr. Pow. Syst. Res. 2008, 78, 1361-1368. [CrossRef]

33. Bahmani, F. An efficient scenario-based and fuzzy self-adaptive learning particle swarm optimization approach for dynamic economic emission dispatch considering load and wind power uncertainties. Energy 2013, 50, 232-244. [CrossRef]

34. Hau, E. Wind Turbines: Fundamentals, Teachnologies, Application, Economics; Springer: Berlin/Heidelberg, Germany, 2013.

35. Lange, S.E.L.; Højstrup, R. Barthelmie, J. The wind speed profile at offshore wind farm sites. Naples 2003, 10, 19-33.

36. Blaabjerg, C. Power electronics as efficient interface in dispersed power generation systems. IEEE T Power Electr. 2004, 19, 1184-1194. [CrossRef]

37. Tong, W. Wind Power Generation and Wind Turbine Design; WIT Press: Southampton, UK, 2010.

38. Gasch, J.T. Wind Power Plants: Fundamentals, Design, Construction and Operation; Springer: Berlin/Heidelberg, Germany, 2011.

39. Pishvaee, T. Credibility-based fuzzy mathematical programming model for green logistics design under uncertainty. Comput. Ind. Eng. 2012, 62, 624-632. [CrossRef]

40. Torabi, E.H. An interactive possibilistic programming approach for multiple objective sully chain master planning. Fuzzy Set Syst. 2008, 23, 193-214. [CrossRef]

41. Zhang, G.; Guo, L. Opportunistic maintenance for wind turbines considering imperfect, reliability-based maintenance. Renew. Energy 2017, 103, 606-612. [CrossRef]

42. Vestas 90-3 MW. Vestas Wind Systems A/S. 2017. Available online: https://www.vestas.com/en/products/2-mw-platform/v902_0_mw (accessed on 21 July 2017). 